\title{
Factors associated with risk of sarcopenia in older adults
}

\author{
Fatores associados com o risco de sarcopenia em idosos
}

\section{AUTHOR'S \\ Daniel Vicentini de Oliveira ${ }^{1}$ (D) \\ Renan Ferreira de Oliveira ${ }^{2}$ (D) \\ Matheus Amarante do Nascimento ${ }^{3}$ (D) \\ Gabriel Lucas Morais Freire ${ }^{1}$ (D) \\ José Roberto Andrade do Nascimento Junior ${ }^{4}$ (D) \\ Rogéria Vicentini de Oliveira ${ }^{5}$ (D) \\ Sônia Maria Marques Gomes Bertolinis ${ }^{5}$ (D) \\ 1 Universidade Estadual de Maringá, Programa \\ de Pós-Graduação em Educação Física, Maringá, \\ Paraná, Brasil. \\ 2 Centro Universitário Metropolitano de Maringá, \\ Programa de Graduação em Educação Física, \\ Maringá, Paraná, Brasil \\ 3 Universidade Estadual do Paraná, Departamento \\ de Educação Física, Paranavaí, Paraná, Brasil. \\ 4 Universidade Federal do Vale do São Francisco, \\ Programa de Pós-Graduação em Educação Física, \\ Petrolina, Pernambuco, Brasil. \\ 5 Universidade Cesumar, Programa de Pós- \\ Graduação em Promoção da Saúde, Maringá, \\ Paraná, Brasil.}

\section{CORRESPONDING}

Daniel Vicentini de Oliveira

d.vicentini@hotmail.com

Avenida Guedner, 1610, Maringá, Paraná, Brasil.

Zip code: 87050-900.

DOI

10.12820/rbafs.26e0196

\section{(cc) BY}

This work is licensed under a Creative Commons Attribution 4.0 International License

\begin{abstract}
This study aimed to assess the factors associated with the risk of sarcopenia in older adults who attend social groups. This is a cross-sectional conducted with 207 older adults. A sociodemographic questionnaire, the International Physical Activity Questionnaire (IPAQ) and the SARC-f questionnaire were used as instruments. Data analysis was carried out by using the chi-squared test and the Binary Logistic Regression $(\mathrm{p}<0.05)$. The results showed a significant association of the risk of sarcopenia with the education level $(p=0,016)$. There was a significant difference among the groups in self-perceived health $(\mathrm{p}=0.001)$, health perception compared to older adults of the same age $(\mathrm{p}=$ $0.001)$, amount of medications used $(p=0.001)$, history of falls $(p=0.001)$ and near-falls $(p=0.001)$. No significant difference was found in the risk of sarcopenia with level of physical activity. When comparing the ratios of diseases reported according to the risk of sarcopenia, there was a significant difference in heart disease $(p=0.001)$, systemic arterial hypertension $(p=0.001)$, stroke $(p=0.001)$, diabetes $(p=0.049)$, osteoarthritis $(p=0.001)$, lung disease $(p=0.034)$, depression $(p=0.001)$ and osteoporosis $(\mathrm{p}=0.001)$. The logistic regression revealed that the older adults who had no history of falls and reported no heart disease, lung disease, depression or osteoporosis were more likely to have no risk of sarcopenia. Therefore, it was concluded that the education level and health conditions reported by the older adults can be considered as factors associated with the risk of sarcopenia. The level of physical activity is not a factor associated with the indication of sarcopenia.
\end{abstract}

Keywords: Sarcopenia; Aging; Social groups; Educational status; Health.

RESUMO

Este estudo teve como objetivo avaliar os fatores associados ao risco de sarcopenia em idosos que frequentam grupos sociais. Trata-se de um estudo transversal realizado com 207 idosos. Utilizaram-se como instrumento os questionários sociodemográficos, o International Physical Activity Questionnaire (IPAQ) e o SARC-f. A análise dos dados foi realizada pelo teste do qui-quadrado e pela regressão logística binária $(p<0,05)$. Os resultados mostraram associação significante do risco de sarcopenia com o nivel de escolaridade $(p=0,016)$. Houve diferença significante entre os grupos com e sem risco de sarcopenia em relação à autopercep̧ão de saúde $(p=0,001)$, percepção de saúde em comparação com idosos da mesma idade $(p=0,001)$, quantidade de medicamentos utilizados $(p=0,001)$, histórico de quedas $(p=0,001)$ e quase quedas $(p=0,001)$. Não foi encontrada diferença significativa do risco de sarcopenia com nivel de atividade física. Ao comparar as proporções de doenças relatadas de acordo com o risco de sarcopenia, houve diferença significante entre cardiopatia $(p=0,001)$, hipertensão arterial sistêmica $(p=0,001)$, acidente vascular cerebral $(p=0,001)$, diabetes $(p=0,049)$, osteoartrite $(p=0,001)$, doença pulmonar $(p=0,034)$, depressão $(p=0,001)$ e osteoporose $(p=0,001)$. A regressão logística revelou que os idosos que não tinham histórico de quedas e não relataram cardiopatia, doença pulmonar, depressão ou osteoporose apresentaram maior probabilidade de não ter risco de sarcopenia. Concluiu-se que o nivel de escolaridade e as condiçóes de saúde relatadas pelos idosos podem ser considerados fatores associados ao risco de sarcopenia. O nivel de atividade física não é um fator associado ao risco de sarcopenia.

Palavras-chave: Sarcopenia; Envelhecimento; Grupos sociais; Escolaridade; Saúde.

\section{Introduction}

The natural aging process is related to reductions from $1 \%$ up to $3 \%$ in different biological systems each year, especially after the fifth decade of life ${ }^{1,2}$. These reductions refer to changes in body composition components, muscle mass reduction, associated with low levels of muscular strength so-called sarcopenia ${ }^{3}$. Sarcopenia has been extensively investigated, since it is related to the loss of autonomy ${ }^{4}$, increase in the number of falls and fractures ${ }^{5}$, decreased bone mineral density ${ }^{6}$, reduced quality of life, fragility, functional disability and premature death ${ }^{7}$. 
Information available in the literature indicates that its prevalence might vary between $7 \%$ and $50 \%$ in the older adults ${ }^{8}$, that is, $20 \%$ among women and $12 \%$ among men in Brazil ${ }^{9}$. Its emergence and development can be triggered by lack of physical activity, sedentary behavior, decreased protein synthesis, hormonal changes, as well as loss of motor neurons ${ }^{3}$, which is characterized, in etiological terms, as a multifactorial disease. It is worth mentioning that sarcopenia is a public health problem, considering that sarcopenic older adults generally need special care, which leads to increased costs for the public health system ${ }^{10,11}$.

Over the years, several studies have been carried out in order to analyze the factors that might be associated with sarcopenia, including advanced age, low body mass index, presence of heart disease ${ }^{12}$, stress, smoking habit, dementia, marital status, blood pressure ${ }^{13}$, chronic renal disease ${ }^{14}$ and low level of physical activity ${ }^{15}$. Thus, understanding the possible factors associated with sarcopenia is extremely important so as to combat this disease that affects the older adults and provide them with an independent and dignified life. Although the aforementioned studies have analyzed the possible associated factors with sarcopenia, these investigations were conducted in countries other than Brazil, such as Japan, Sweden, Korea, and Peru. Thus, it is crucial to conduct investigations in Brazil, especially in different states of the country, in order to better elucidate this subject. Taking into account that the practice of physical activity generates numerous benefits for the elderly population and that there is a need for updating by health professionals to this population that has increased exponentially.

Therefore, this study aimed at assessing the physical activity and factors associated with the risk of sarcopenia in older adults who attend social groups. The hypothesis would be that low physical activity, some socio-demographic variables, such as low education and income, in addition to female sex and health variables would be associated with the highest risk of sarcopenia in the older adults.

\section{Methods}

The finite population sampling was used to calculate the sample size with a confidence level of $95 \%$, an estimation error of $5 \%$, and an expected ratio of $50 \%{ }^{16}$. The participation of approximately 368 elderly people inserted in the 14 social groups was estimated, thus, requiring a minimum sample of 207 older adults by considering possible sample losses.

The older adults of both sexes engaged in social group activities were included through a project named 'active life'. Based on the researcher's perception and/ or the participants' self-report, the individuals who had visual or hearing deficits that that could prevent participation in the study were excluded. The older adults who used walking gears, hip, knee or ankle prostheses or the ones who had undergone major surgeries less than three months before were also excluded.

Therefore, the sample consisted of 207 subjects. The sample of 207 elderly people was chosen intentionally and by convenience. The association analysis considered a statistical power of $80 \%$ and Odds Ratio (OR) of 1.3 .

This study was approved by the Research Ethics Committee of the University Center named Centro Universitário Metropolitano de Maringá (UNIFAMMA) registered by the number 2.997.577/2018.

Data collection was carried out with 14 social groups that attend the older adults in the city of $\mathrm{Sa}-$ randi, Paraná. Such groups were registered in the Department of Social Services of this city which involves all the sites that offer this kind of service. In this social groups, handcraft, dance, stretching, functional exercises, and singing activities are carried out.

Initially, the person responsible for each social group was contacted in order to obtain the authorization to perform the research, and then a list was requested with the schedule of the activities of each group. The older adults of the social groups were approached before or after the classes, so that they were informed about the procedures to which they would be submitted, and those who accepted to participate in the research signed a written informed consent form.

Before data collection, the researchers were trained and a pilot with 5 older adults was carried out.

The study was performed throughout 90 days. The first 60 days were used for data collection. The following items were evaluated: physical activity level, sedentary behavior, risk of sarcopenia, and the socio-demographic profile of the participants. The questionnaires were applied by interviewing the individuals so as to avoid possible reading errors by the participant; each each interview, on average, 10 min per participant.

A semi-structured questionnaire was created and applied by the authors to assess the sociodemographic, health and practice profiles of the groups' activities. This instrument consisted of questions related to the age group, education, marital status, smoking, length 
of presence in the group, activities performed in the group, average income, retired or not, self-perceived health and perception in relation to older adults of the same age, use of medications, falls, situations of near falls, number of times they participate in group activities per week and self-reported diseases.

TThe physical activity level was measured by applying the short version of the International Physical Activity Questionnaire (IPAQ). Following the levels established by Matsudo et $\mathrm{al}^{17}$.

SARC- $\mathrm{f}^{18}$ was used in order to evaluate the risk of sarcopenia. This questionnaire includes five components: strength (if the individual could lift $5.5 \mathrm{lb}$ ), walking (if the individual could walk across a living room or in his/her bedroom), rising from a chair (if the individual could rise from a chair), climbing stairs (if the individual could climb a flight of 10 stairs) and falls (if the individual had fallen down in the past year). The scores range from zero to 2 points. Considering the first four components, this is the interpretation: zero = none, $1=$ some and $2=$ a lot or unable to perform the task. Regarding the last one, the score is: zero $=$ no falls in the past year, $1=1-3$ falls in the past year, and $2=$ 4 or more falls in the past year. A total score of four or more points including the five components were risk of sarcopenia.

The analysis was performed by using a descriptive inferential statistics approach. The Chi-squared test was applied to investigate proportional differences in socio-demographic variables and health conditions based on the risk of sarcopenia. The Binary Logistic Regression (crude and adjusted analysis) was used to evaluate the associations of socio-demographic variables and health conditions (independent variables) with no risk of sarcopenia (dependent variable) of the older adults. For modeling the regression analysis, only the variables that showed a significance level equal to or less than 0.20 in the Chi-squared test were considered. The model adjustment was verified by using Hosmer-Lemeshow test. Considering the adjusted analysis, a hierarchical approach was adopted, following the backward procedure for introducing variables. A p-value lower than 0.20 was adopted as the criterion for the factor permanence in the adjusted regression analysis. Finally, a final regression model with only those variables of higher statistical significance was obtained. A significance level of $\mathrm{p}<0.05$ and a confidence interval (CI) of $95 \%$ by calculating the adjusted odds ratios were considered. In addition, a post hoc statistical power analy- sis in $G^{*}$ Power $3.1 .9^{19}$ revealed our statistical power to be $79.6 \%$ based on our sample of 207 participants, an Odds Ratio of 1.5 , and a $0.05 p$ value. All analysis was conducted through SPSS 22.0 software.

\section{Results}

Older men and women (197 women and 10 men) participated in the survey, with a mean age of $66.32 \pm$ 6.19 years. Note prevalence of older adults with a partner (59.4\%), aged between 60 and 70 years (79.7\%), monthly income of one minimum wage $(75.8 \%)$, white $(82,6 \%)$, retired $(63.3 \%)$ and who do not currently smoke (67.6\%). Regarding education, 37.2\% reported incomplete primary education and $37.2 \%$ reported complete primary education.

Regarding the health profile of older adults who frequent social groups in the city of Sarandi, it was found that most older adults reported a good health perception (47.3\%), perceived themselves with better health than older adults of the same age (70\%), used two or more medications (43.5\%), had no history of falls (63.8\%), but had a history of almost falls in the last six months $(67.6 \%)$.

In addition, $57.0 \%$ of the older adults have been attending social groups for more than three years and $86.0 \%$ have been attending groups two to three times a week. It was also found a prevalence of older adults with active level of physical activity (93.2\%) and who do not present risk of sarcopenia (75.8\%).

They observed that the majority of the older adults do not have heart disease (78.7\%), stroke (89.4\%), diabetes (76.3\%), cancer (92.3\%), osteoarthritis (68.1\%), diseases lung (92.8\%), depression (79.2\%) and osteoporosis (82.1\%), however, $55.6 \%$ of the participants reported having arterial hypertension.

According to the findings, the older adults do not perform vigorous activities $(\mathrm{Md}=0.0)$, but perform light activities $(\mathrm{Md}=4.0)$ and moderate activities (2.0) a few times a week. Specifically, there was a median of 60 and 180 min per day and per week of light physical activities, and 60 and 120 min of moderate physical activity per day and per week. Regarding sedentary behavior, the average was 240 minutes without sitting for a week and 360 minutes without a weekend. Further, it was found a median of 2.0 for the risk of sarcopenia.

When comparing the ratios of the socio-demographic variables according to the risk of sarcopenia (Table 1), a significant difference among the groups was found only regarding education $(p=0.016)$, indi- 
cating that there is a higher proportion of older adults with no risk of sarcopenia with higher education level. Considering the other socio-demographic variables ( $\mathrm{p}$ $>0.05)$, there was no significant difference among the groups.

When comparing the ratios of the health conditions according to the risk of sarcopenia (Table 1), there was a significant difference among the groups in self-perceived health $(p=0.001)$, health perception compared to older adults of the same age $(p=0.001)$, amount of medications used $(\mathrm{p}=0.001)$, history of falls $(\mathrm{p}=$ $0.001)$ and near-falls $(p=0.001)$. These results seem to indicate a higher proportion of older adults with risk of sarcopenia who take more medicines (72.0\%) and who have already had a history of falls (76.0\%) and near falls (92.0\%), whereas there is a higher proportion of older adults with no risk of sarcopenia with good self-perceived health (54.8\%) and who perceived themselves as having better health than the older adults of the same age $(76.4 \%)$.

When comparing the ratios of diseases reported according to the risk of sarcopenia (Table 2), there was a significant difference in heart disease $(p=0.001)$, systemic arterial hypertension $(\mathrm{p}=0.001)$, stroke $(\mathrm{p}=$ $0.001)$, diabetes $(p=0.049)$, osteoarthritis $(p=0.001)$, lung disease $(p=0.034)$, depression $(p=0.001)$ and osteoporosis $(p=0.001)$. These results indicate a higher proportion of older adults with no risk of sarcopenia who reported no heart disease (85.4\%), stroke (93.6\%), diabetes (79.6\%), lung disease (94.9), depression (95.4\%) or osteoporosis (89.2\%), whereas there is a higher proportion of older adults with risk of sarcopenia who reported having systemic arterial hypertension (72.0\%) and osteoarthritis (60.0\%).

When analyzing the association (crude and adjusted) related to no risk of sarcopenia with the socio-demographic variables and health conditions (Table 3), considering the crude analysis, a significant association was found ( $p<0.05)$ with the self-perceived health, health perception compared to older adults of the same age, amount of medication, history of falls and near-falls, heart disease, systemic arterial hypertension, stroke, diabetes, osteoarthritis, lung disease, depression and osteoporosis.

When the analysis was adjusted for all variables ( $\mathrm{Ta}-$ ble 4$)$, they remained associated $(p<0.05)$ with no risk of sarcopenia, history of falls, heart disease, lung disease, depression or osteoporosis. It is noteworthy that the older adults who had no history of falls and reported
Table 1 - Comparison of the ratios of the sociodemographic and health variables of the older adults attending social groups in the city of Sarandi, Parana, Brazil, according to the risk of sarcopenia $(n=207)$.

\begin{tabular}{|c|c|c|c|c|}
\hline \multirow{3}{*}{ Variables } & \multicolumn{2}{|c|}{ Risk of sarcopenia } & \multirow{3}{*}{$\chi^{2}$} & \multirow{3}{*}{$\mathrm{p}$} \\
\hline & No $(n=157)$ & Yes $(n=50)$ & & \\
\hline & $f(\%)$ & $f(\%)$ & & \\
\hline \multicolumn{5}{|l|}{ Sex } \\
\hline Male & $9(5.7)$ & $1(2.0)$ & 1.144 & 0.284 \\
\hline Female & $148(94.3)$ & $49(98.0)$ & & \\
\hline \multicolumn{5}{|l|}{ Age group } \\
\hline 60 to 70 years of age & $127(80.9)$ & $38(76.0)$ & 0.561 & 0.454 \\
\hline Over 70 years of age & 30 (19.1) & $12(24.0)$ & & \\
\hline \multicolumn{5}{|l|}{ Marital Status } \\
\hline Having a partner & $97(61.8)$ & $26(52.0)$ & 1.505 & 0.220 \\
\hline Not having a partner & $60(38.2)$ & $24(48.0)$ & & \\
\hline \multicolumn{5}{|l|}{ Color } \\
\hline White & $129(82.2)$ & $42(84.0)$ & 0.089 & 0.766 \\
\hline Black & $28(17.8)$ & $8(16.0)$ & & \\
\hline \multicolumn{5}{|l|}{ Education } \\
\hline Illitarate & $14(8.9)$ & $9(18.0)$ & 3.936 & $0.048^{*}$ \\
\hline Incomplete elementary ed. & $57(36.3)$ & $20(40.0)$ & & \\
\hline Complete elementary ed. & $61(38.9)$ & $16(32.0)$ & & \\
\hline Complete high school & $25(15.9)$ & $5(10.0)$ & & \\
\hline \multicolumn{5}{|l|}{ Retirement } \\
\hline Yes & $97(61.8)$ & $34(68.0)$ & 0.631 & 0.427 \\
\hline No & $60(38.2)$ & $16(32.0)$ & & \\
\hline \multicolumn{5}{|l|}{ Monthly income } \\
\hline 1 to 2 minimum wages & $114(72.6)$ & $43(86.0)$ & 3.711 & 0.054 \\
\hline Over 2 minimum wages & $43(27.4)$ & $7(14.0)$ & & \\
\hline \multicolumn{5}{|l|}{ Self-perceived health } \\
\hline Good & $86(54.8)$ & $12(24.0)$ & & \\
\hline Regular & $54(34.4)$ & $30(60.0)$ & 10.381 & $0.001^{*}$ \\
\hline Bad & $17(10.8)$ & $8(16.0)$ & & \\
\hline \multicolumn{5}{|c|}{ Health perception compared with other older adults } \\
\hline Good & $86(54.8)$ & $12(24.0)$ & & \\
\hline Regular & $54(34.4)$ & $30(60.0)$ & 10.381 & $0.001^{*}$ \\
\hline Bad & $17(10.8)$ & $8(16.0)$ & & \\
\hline \multicolumn{5}{|l|}{ Medication } \\
\hline None & $37(23.6)$ & $3(6.0)$ & & \\
\hline 1 to 2 & $66(42.0)$ & $11(22.0)$ & 20.165 & $0.001^{*}$ \\
\hline Over 2 & $54(34.4)$ & $36(72.0)$ & & \\
\hline \multicolumn{5}{|l|}{ Falls } \\
\hline Yes & $37(23.6)$ & $38(76.0)$ & 45.125 & $0.001^{*}$ \\
\hline No & $120(76.4)$ & $12(24.0)$ & & \\
\hline \multicolumn{5}{|l|}{ Near-falls } \\
\hline Yes & $94(59.9)$ & $46(92.0)$ & 17.881 & $0.001^{*}$ \\
\hline No & $63(40.1)$ & $4(8.0)$ & & \\
\hline \multicolumn{5}{|l|}{ Time of physical activity } \\
\hline Up to 1 year & $45(28.7)$ & $21(42.0)$ & 3.544 & \\
\hline From 1.1 to 3 years & $17(10.8)$ & $6(12.0)$ & & 0.060 \\
\hline Over 3 years & $95(60.5)$ & $23(46.0)$ & & \\
\hline \multicolumn{5}{|l|}{ Weekly attendance } \\
\hline Once & $23(14.6)$ & $6(12.0)$ & 0.221 & 0.638 \\
\hline 2 to 3 times & $134(85.4)$ & $44(88.0)$ & & \\
\hline \multicolumn{5}{|l|}{ Physical activity level } \\
\hline Active & $148(94.3)$ & $45(90.0)$ & & \\
\hline Poorly active & $9(5.7)$ & $5(10.0)$ & 1.095 & 0.295 \\
\hline
\end{tabular}

* $p<0.05=$ Chi-squared test for the ratios. 
Table 2 - Comparison of the ratios of the diseases reported by the older adults attending social groups in the city of Sarandi, Parana, Brazil, according to the risk of sarcopenia $(n=207)$.

\begin{tabular}{|c|c|c|c|c|}
\hline \multirow{3}{*}{ Variables } & \multicolumn{2}{|c|}{ Risk of sarcopenia } & \multirow{3}{*}{$\chi^{2}$} & \multirow{3}{*}{$\mathrm{p}$} \\
\hline & No $(n=157)$ & Yes $(\mathrm{n}=50)$ & & \\
\hline & $f(\%)$ & $f(\%)$ & & \\
\hline \multicolumn{5}{|c|}{ Heart Disease } \\
\hline Yes & $23(14.6)$ & $21(42.0)$ & \multirow{2}{*}{16.498} & \multirow{2}{*}{$0.001^{*}$} \\
\hline No & $134(85.4)$ & $29(58.0)$ & & \\
\hline \multicolumn{5}{|c|}{ Systemic arterial hypertension } \\
\hline Yes & $79(50.3)$ & $36(72.0)$ & \multirow{2}{*}{7.220} & \multirow{2}{*}{$0.007^{*}$} \\
\hline No & $78(49.7)$ & $14(28.0)$ & & \\
\hline \multicolumn{5}{|l|}{ Stroke } \\
\hline Yes & $10(6.4)$ & $12(24.0)$ & \multirow{2}{*}{12.410} & \multirow{2}{*}{$0.001^{*}$} \\
\hline No & $147(93.6)$ & $38(76.0)$ & & \\
\hline \multicolumn{5}{|l|}{ Diabetes } \\
\hline Yes & $32(20.4)$ & $17(34.0)$ & \multirow{2}{*}{3.892} & \multirow{2}{*}{$0.049^{*}$} \\
\hline No & $125(79.6)$ & $33(66.0)$ & & \\
\hline \multicolumn{5}{|l|}{ Cancer } \\
\hline Yes & $13(8.3)$ & $3(6.0)$ & \multirow{2}{*}{0.276} & \multirow{2}{*}{0.599} \\
\hline No & $144(91.7)$ & $47(94.0)$ & & \\
\hline \multicolumn{5}{|c|}{ Osteoarthritis } \\
\hline Yes & $36(22.9)$ & $30(60.0)$ & \multirow{2}{*}{23.995} & \multirow{2}{*}{$0.001^{*}$} \\
\hline No & $121(77.1)$ & $20(40.0)$ & & \\
\hline \multicolumn{5}{|c|}{ Lung disease } \\
\hline Yes & $8(5.1)$ & $7(14.0)$ & \multirow{2}{*}{4.474} & \multirow{2}{*}{$0.034^{*}$} \\
\hline No & 149 (94.9) & $43(86.0)$ & & \\
\hline \multicolumn{5}{|c|}{ Depression } \\
\hline Yes & $23(14.6)$ & $20(40.0)$ & \multirow{2}{*}{14.808} & \multirow{2}{*}{$0.001^{*}$} \\
\hline No & $134(85.4)$ & $30(60.0)$ & & \\
\hline \multicolumn{5}{|c|}{ Osteoporosis } \\
\hline Yes & $17(10.8)$ & $20(40.0)$ & \multirow{2}{*}{21.985} & \multirow{2}{*}{$0.001^{*}$} \\
\hline No & $140(89.2)$ & $30(60.0)$ & & \\
\hline
\end{tabular}

* $\mathrm{p}<0.05=$ Chi-squared test for the ratios.

having no heart disease, lung disease, depression or osteoporosis were more likely to have no risk of sarcopenia.

\section{Discussion}

The main findings of the present study are related to the fact that the older adults with higher education level, good self-perceived health, those who perceive themselves with better health than older adults of the same age, the ones with no history of falls or near-falls, nor heart disease, stroke, diabetes, lung disease, depression or osteoporosis had no risk of sarcopenia.

These results corroborate the strong relationship between good health, in general, and absence of diseases, in the specific case of sarcopenia.A recent population-based investigation showed that pre-sarcopenic and sarcopenic older adults are more frequently smokers with a higher
Table 3 - Factors associated with no risk of sarcopenia in the older adults attending social groups in the city of Sarandi, Parana, Brasil $(n=207)$.

\begin{tabular}{|c|c|c|}
\hline Variables & OR gross [C.I 95\%] & OR adjusted [C.I 95\%] \\
\hline \multicolumn{3}{|l|}{ Education } \\
\hline Illiterate & 1 & 1 \\
\hline Incomplete elementary & $1.83[0.68-4.88]$ & - \\
\hline Complete elementary & $2.45[0.90-6.67]$ & - \\
\hline Complete secondary & $3.21[0.89-11.49]$ & - \\
\hline \multicolumn{3}{|l|}{ Monthly income } \\
\hline 1 to 2 minimum wages & 1 & 1 \\
\hline Over 2 minimum wages & $2.31[0.96-5.54]$ & $2,69[0.86-8.42]$ \\
\hline \multicolumn{3}{|l|}{ Self-perceived health } \\
\hline Good & 1 & 1 \\
\hline Regular & $0.25[0.11-0.53]^{*}$ & - \\
\hline Bad & $0.29[0.10-0.83]^{*}$ & - \\
\hline \multicolumn{3}{|c|}{ Health perception compared to other older adults } \\
\hline Worse & 1 & 1 \\
\hline Equal & $1.70[0.54-5.37]$ & - \\
\hline Better & $4.80[1.64-14.00]^{*}$ & - \\
\hline \multicolumn{3}{|l|}{ Medication } \\
\hline None & 1 & 1 \\
\hline 1 to 2 & $0.48[0.12-1.85]$ & - \\
\hline Over 2 & $0.12[0.03-0.42]^{*}$ & - \\
\hline \multicolumn{3}{|l|}{ Falls } \\
\hline Yes & 1 & 1 \\
\hline No & $10.27[4.86-21.66]^{*}$ & $10.844[4.156-28.294]^{*}$ \\
\hline \multicolumn{3}{|l|}{ Near-falls } \\
\hline Yes & 1 & 1 \\
\hline No & $7.70[2.64-22.47]^{*}$ & $3.39[0.94-12.16]$ \\
\hline \multicolumn{3}{|l|}{ Time of physical activity } \\
\hline Up to 1 year & 1 & 1 \\
\hline 1.1 to 3 years & $1.32[0.45-3.83]$ & - \\
\hline Over 3 years & $1.92[0.96-3.84]$ & - \\
\hline \multicolumn{3}{|l|}{ Heart disease } \\
\hline Yes & 1 & 1 \\
\hline No & $4.21[2.06-8.62]^{*}$ & $2.76[1.041-7.34]^{*}$ \\
\hline \multicolumn{3}{|c|}{ Systemic arterial hypertension } \\
\hline Yes & 1 & 1 \\
\hline No & $2.53[1.27-5.07]^{*}$ & - \\
\hline \multicolumn{3}{|l|}{ Stroke } \\
\hline Yes & 1 & 1 \\
\hline No & $4.64[1.86-11.55]^{*}$ & - \\
\hline \multicolumn{3}{|l|}{ Diabetes } \\
\hline Yes & 1 & 1 \\
\hline No & $2.11[1.00-4.06]^{*}$ & - \\
\hline \multicolumn{3}{|l|}{ Osteoarthritis } \\
\hline Yes & 1 & 1 \\
\hline No & $5.04[2.56-9.92]^{*}$ & - \\
\hline \multicolumn{3}{|l|}{ Lung disease } \\
\hline Yes & 1 & 1 \\
\hline No & $3.03[1.04-8.83]^{*}$ & $4.82[1.021-22.80]^{*}$ \\
\hline \multicolumn{3}{|l|}{ Depression } \\
\hline Yes & 1 & 1 \\
\hline No & $3.88[1.89-7.96]^{*}$ & $4.28[1.58-11.53]^{*}$ \\
\hline \multicolumn{3}{|l|}{ Osteoporosis } \\
\hline Yes & 1 & 1 \\
\hline No & $5.49[2.57-11.70]^{*}$ & $5.28[1.93-14.39]^{*}$ \\
\hline
\end{tabular}


history of hospitalization; they are less active and have a low quality diet, in addition to having worse physical condition and higher prevalence of fractures ${ }^{20}$.

When assessing the self-perceived health of the older adults, it was seen that those who have sarcopenia take more medicines and have already had falls or near-falls. Stewart, Saunders and Greig ${ }^{21}$ showed in their systematic reviews that regular physical exercise practice can effectively improve health, thus, increasing lean body mass and neuromuscular functions, and avoiding possible falls, as well as improving activities of daily living and self-perceived health.

Considering the correlation between chronic diseases and sarcopenia, it was seen that the older adults who do not report sarcopenia, do not report having chronic diseases either. On the other hand, there is a higher number of older adults who reported having sarcopenia and other chronic diseases, such as hypertension and arthritis. Therefore, regular physical exercise habits might be a protective factor for the control of sarcopenia and other chronic diseases ${ }^{22}$. In general, the inclusion of the older adults in physical activity programs has socialization as one of its central axes ${ }^{23}$. Thus, physical activity is not only limited to physiological but also psychological benefits, so that the older adults feel included in the group and, consequently, valued for practice ${ }^{24}$.

The association between low education level and risk of sarcopenia found in the present study is corroborated by other researchers ${ }^{25}$ in a population-based study with Brazilian older adults; an association possibly explained by the fact that low education level has been related to cases of malnutrition, which, in turn, could enhance the emergence of sarcopenia ${ }^{26}$.

Regarding the practice of physical exercises, most of the participants included in this study were physically active, which did not allow a significant association to be found between the risk of sarcopenia and physical activity level, as found in other investigations ${ }^{20,27-29}$. The research by Confortin and collaborators ${ }^{27}$, for example, showed that older women who become insufficiently active or remain insufficiently active over the years are more likely to have sarcopenia. Martinez et al. ${ }^{29}$, after assessing 110 hospitalized older adults, found that the highest frequency of sarcopenia occurred in those who reported a low level of physical activity before being hospitalized. Other researchers found that physical inactivity was the indicator of sarcopenia most related to fragility in the older adutls ${ }^{30}$.
The present study has some limitations. The SARC-f questionnaire is an instrument used only as an risk of sarcopenia, reasonably different from a more specialized technique, such as the dual-energy r-ray absorptiometry, widely used for the diagnosis of sarcopenia. This is a cross-sectional study, which makes it impossible to infer the mechanism of cause and effect among the associations found.

Finally, we conclude that social groups with high education level and health conditions reported by the participants of the present study are not associated with the risk of sarcopenia. It is worth mentioning that the older adults who did not report negative health conditions were more likely to have no indication of sarcopenia. The level of physical activity is not a factor associated with the indication of sarcopenia.

\section{Conflict of interest}

The authors declare no conflict of interest.

\section{Author's contributions}

Oliveira DV and Oliveira RF participated in the initial study design, writing, critical text review and data collection. Nascimento MA, Freire GLM and Oliveira RV were responsible for searching the literature and writing. Nascimento Júnior JRA and Bertolini SMMG participated in the critical review of the text.

\section{Referências}

1. He X, Li Z, Tang X, Zhang L, Wang L, He Y, et al. Ageand sex-related differences in body composition in healthy subjects aged 18 to 82 years. Medicine (Baltimore). 2018;97(25):e11152.

2. Manini TM, Clark BC. Dynapenia and aging: an update. J Gerontol A Biol Sci Med Sci. 2011;67(1):28-40.

3. Cruz-Jentoft AJ, Bahat G, Bauer J, Boirie Y, Bruyère $O$, Cederholm T, et al. Sarcopenia: Revised European Consensus on Definition and Diagnosis. Age Ageing. 2019;48(1):16-31.

4. Cesari M, Rolland Y, Abellan Van Kan G, Bandinelli S, Vellas B, Ferrucci L. Sarcopenia-related parameters and incident disability in older persons: results from the "invecchiare in Chianti" study. J Gerontol A Biol Sci Med Sci. 2014;70(4):457-63.

5. Pagotto V, Silveira EA. Applicability and agreement of different diagnostic criteria for sarcopenia estimation in the elderly. Arch Gerontol Geriatr. 2014;59(2):288-94.

6. Pereira FB, Leite AF, Paula AP. Relationship between presarcopenia, sarcopenia and bone mineral density in elderly men. Arch Endocrinol Metabol. 2015;59(1):59-65.

7. Lang T, Streeper T, Cawthon P, Baldwin K, Taaffe DR, Harris T. Sarcopenia: etiology, clinical consequences, intervention, and assessment. Osteoporos Int. 2010;21(4):543-59.

8. Bijlsma A, Meskers C, Ling C, Narici M, Kurrle S, Cameron I, et al. Defining sarcopenia: the impact of different diagnostic criteria on the prevalence of sarcopenia in a large middle aged cohort. Age. 2013;35(3):871-81. 
9. Diz JBM, Leopoldino AAO, Moreira BdS, Henschke N, Dias RC, Pereira LSM, et al. Prevalence of sarcopenia in older Brazilians: A systematic review and meta-analysis. Geriatr Gerontol Int. 2017;17(1):5-16.

10. Beaudart C, Zaaria M, Pasleau F, Reginster J-Y, Bruyère O. Health outcomes of sarcopenia: a systematic review and meta-analysis. PloS one. 2017;12(1):e0169548.

11. Brandão GS, Camelier FW, Sampaio AA, Brandão GS, Silva AS, Gomes GS, Donner CF, et al. Association of sleep quality with excessive daytime somnolence and quality of life of elderlies of community. Multidiscip Respir Med. 2018;13(1).

12. Kim H, Suzuki T, Kim M, Kojima N, Yoshida Y, Hirano $\mathrm{H}$, et al. Incidence and predictors of sarcopenia onset in community-dwelling elderly Japanese women: 4-year followup study. J Am Medical Dir Assoc. 2015;16(1).

13. Sternäng $O$, Reynolds CA, Finkel D, Ernsth-Bravell M, Pedersen NL, Dahl Aslan AK. Factors associated with grip strength decline in older adults. Age Ageing. 2014;44(2):269-74.

14. Moon SJ, Kim TH, Yoon SY, Chung JH, Hwang H-J. Relationship between stage of chronic kidney disease and sarcopenia in Korean aged 40 years and older using the Korea National Health and Nutrition Examination Surveys (KNHANES IV-2, 3, and V-1, 2), 2008-2011. PloS one. 2015;10(6):e0130740.

15. Tramontano A, Veronese N, Sergi G, Manzato E, RodriguezHurtado D, Maggi S, et al. Prevalence of sarcopenia and associated factors in the healthy older adults of the Peruvian Andes. Arch Gerontol Geriatr. 2017;68:49-54.

16. Richardson R, Peres JS, Wanderley J, Correia L, Peres MHM. Epistemologia do trabalho científico M Pesquisa social: métodos e técnicas São Paulo: Atlas. 1999.

17. Matsudo V, Matsudo SM, Araújo TL, Andrade DR, Oliveira LC, Hallal PC. Time trends in physical activity in the state of Sao Paulo, Brazil: 2002-2008. Med Sci Sports Exerc. 2010;42(12):2231-6.

18. Woo J, Leung J, Morley JE. Validating the SARC-F: A suitable community screening tool for sarcopenia? J Am Med Direct Assoc. 2014;15(9):630-4.

19. Faul F, Erdfelder E, Lang AG, Buchner A. GPower 3: A flexible statistical power analysis program for the social, behavioral, and biomedical sciences. Beha Res Methods. 2007;39(2):175-91.

20. Trajanoska K, Schoufour JD, Darweesh SK, Benz E, MedinaGomez C, Alferink LJ, et al. Sarcopenia and its clinical correlates in the general population: the Rotterdam Study. J Min Rese. 2018;33(7):1209-18.
21. Larsson L, Degens H, Li M, Salviati L, Lee Yi, Thompson W, et al. Sarcopenia: aging-related loss of muscle mass and function. Physiol Rev. 2019;99(1):427-511.

22. Akune T, Muraki S, Oka H, Tanaka S, Kawaguchi H, Nakamura K, et al. Exercise habits during middle age are associated with lower prevalence of sarcopenia: the ROAD study. Osteopors Inter. 2014;25(3):1081-8.

23. Castro MR, Lima LHR, Duarte ER. Jogos recreativos para a terceira idade: uma análise a partir da percepção dos idosos. Rev Bras Cienc Esporte. 2016;38(3):283-9.

24. Chung P-K, Zhao Y, Liu J-D, Quach B. A canonical correlation analysis on the relationship between functional fitness and health-related quality of life in older adults. Arch Gerontol Geriatr. 2017;68:44-8.

25. Alexandre TS, Duarte YAO, Santos JLF, Lebrão ML. Prevalência e fatores associados à sarcopenia, dinapenia e sarcodinapenia em idosos residentes no Município de São Paulo-Estudo SABE. Rev Bras Epidemiol. 2019;21:e180009.

26. Fávaro-Moreira NC, Krausch-Hofmann S, Matthys C, Vereecken C, Vanhauwaert E, Declercq A, Bekkering GE, Duyck J. Risk factors for malnutrition in older adults: a systematic review of the literature based on longitudinal data. Adv Nutr. 2016;7(3):507-22.

27. Confortin SC, Ono LM, Barbosa AR, d'Orsi E. Sarcopenia e sua associação com mudanças nos fatores socioeconômicos, comportamentais e de saúde: Estudo EpiFloripa Idoso. Cad Saúde Pública. 2018;34:e00164917.

28. Souza VA, Oliveira D, Barbosa SR, Correa JOA, Colugnati FAB, Mansur HN, et al. Sarcopenia in patients with chronic kidney disease not yet on dialysis: Analysis of the prevalence and associated factors. PLoS One. 2017;12(4):e0176230.

29. Martinez BP, Batista AKMS, Gomes IB, Olivieri FM, Camelier FWR, Camelier AA. Frequency of sarcopenia and associated factors among hospitalized elderly patients. BMC Musculoskelet Disord. 2015;16(1):108.

30. Pritchard JM, Kennedy CC, Karampatos S, Ioannidis G, Misiaszek B, Marr S, Patterson C, Woo T, Papaioannou A. Measuring frailty in clinical practice: a comparison of physical frailty assessment methods in a geriatric out-patient clinic. BMC Geriatr. 2017;17(1):264.

Received: 15/01/2020

Approved: 14/04/2021 